\title{
Recognizing Work as a Priority in Preventing or Ending Homelessness
}

\author{
Gary Shaheen · John Rio
}

Published online: 13 June 2007

(C) Springer Science+Business Media, LLC 2007

\begin{abstract}
The literature speaks to the importance of employment in the lives of homeless individuals and shows how they can be assisted in job seeking (Long \& Amendolia, 2003; Marrone, 2005; Quimby, Drake, \& Becker, 2001; Rio, Russell, Dudasik, \& Gravino, 1999; Rog \& Holupka, 1998; Shaheen, Williams, \& Dennis, 2003; Trutko, Barnow, Beck, Min, \& Isbell, 1998). Some reports suggest it may be effective and worthwhile to offer employment at the earliest stages of engagement to help people who are homeless develop trust, motivation, and hope (Cook et al., 2001; Min, Wong, \& Rothbard, 2004). Practitioners have historically focused on providing people with access to safe and affordable housing and supportive services, usually addressing employment later in the continuum. This practice-oriented report from the field proposes that employment should be offered as early as possible and maintains that facilitating employment is an unrecognized and underutilized practice for preventing and ending homelessness. The paper provides principles, practices, and strategies programs can use to make work a priority.
\end{abstract}

Keywords Homeless · Employment · Work · Housing

\section{Making the Case for Work as a Priority}

Efforts to prevent and end homelessness include a variety of strategies, including those focused upon providing people with access to safe and affordable housing and supportive services (Burt et al. 2004). A relatively small segment of the homeless

\footnotetext{
G. Shaheen $(\bowtie)$

Advocates for Human Potential, Inc, 2-E-Comm Sq./324 Broadway, Albany, NY 12207, USA

e-mail: gshaheen@ahpnet.com

J. Rio

Advocates for Human Potential, Inc, White Plains, NY, USA

e-mail: jrio@ahpnet.com
} 
population, people with disabilities whose homelessness is measured in years or in frequent episodes over time, use a disproportionate share of costly public services (Culhane et al. 2001). In addition to the complex set of disabling conditions they possess, this population is often characterized as "resistant"' to services. Nonetheless, in recent years new approaches are proving effective in engaging people who are chronically homeless in housing and services.

One recently adopted approach is the "Housing First'" model (Tsemberis and Eisenberg 2000; Tsemberis et al. 2004), linked with Assertive Community Treatment (Stein and Santos 1998), which can be modified to serve homeless populations (Dixon et al. 1995). The Housing First approach recognizes that, fundamentally, people will accept services that they want; the role of staff is to help people get those they say they want when they want them, along with intensive wraparound supports. The model has demonstrated impressive housing retention rates of $88 \%$ over 5 years and has been replicated in two current demonstrations, the U.S. Interagency Council on Homelessness Chronic Homeless Initiative and the U.S. Departments of Labor and Housing and Urban Development Initiative to End Chronic Homelessness through Employment and Housing (http://www.dol.gov/ odep/programs/homeless.htm).

Providing a place to live and ensuring access to treatment services for people who are homeless with disabilities are critical steps, but they are insufficient in themselves to prevent or end chronic homelessness. Shelter neither solves homelessness nor prevents further displacement. Absent an adequate supply of affordable housing - and the jobs and income supports needed to sustain households once people have been relocated-remedial efforts are doomed to an endless round of musical chairs (Hopper 2003). The Substance Abuse and Mental Health Services Administration (SAMHSA) has recognized the need to integrate and coordinate employment services as part of a seamless array of services for homeless individuals with serious mental illness (Shaheen et al. 2003). These services support and reinforce each other's efficacy; as individuals with co-occurring disorders receive the treatment they need, they can meet better the challenges of employment. Conversely, as individuals build confidence through employment, they are more motivated to adhere to their treatment regime.

President George W. Bush initiated a goal to end chronic homelessness by 2012 and Congress echoed this goal. In unprecedented actions, the U.S. Interagency Council on Homelessness (ICH) has inspired states and communities not only to develop local plans to end homelessness but also to mirror the federal ICH by establishing their own state interagency councils to ensure that local policy, resources, and results support the goal of ending homelessness. The halfway mark of progress toward this goal is an opportune time to emphasize the importance of employment services-for the next 5 years and beyond. We have a window of opportunity to provide the comprehensive services that homeless people will need to avoid a return to homelessness.

In some communities, unfortunately, the window is a very small one. Continua of Care across the county are making local decisions to use Housing and Urban Development (HUD) funding for permanent housing and the "hard costs" of housing, while seeking funding for services from mainstream programs at the 
federal and local levels. These decisions are made in response to funding incentives that encourage development of permanent housing projects. This does not mean that HUD is getting out of the service business. HUD continues to provide nearly $\$ 32$ million in McKinney-Vento dollars to be used for employment services. Getting people with serious mental illness from the streets to a place of safety where they can deal with all of the other issues in their lives begins with giving them a safe, secure, and affordable place to live. However, meeting this priority need too often means that employment services become something to be addressed at a later time, even if people in the earlier stage of recovery say that they want a job. Although Federal policies direct communities to seek dollars for employment from other mainstream programs (such as labor, mental health, and vocational rehabilitation), in most jurisdictions the cross-systems collaborations necessary for the funding shift to work are not in place. Continuum members often lack the experience they need to leverage service dollars from complex mainstream systems and may not know what funding is available. Knowledge dissemination and a proactive planning response are essential to avoid denying essential employment assistance to those least likely to access it through mainstream workforce services.

In recent years, threats to long-term cash support benefits (including local general assistance payments to homeless people, residents of transitional housing, and permanent housing) are spurring housing providers to encourage homeless individuals' movement toward self-sufficiency. It is certainly in the best interests of housing providers to support strategies that will help their residents earn funds they can contribute to rent payments. Not only can employment strengthen supportive housing by helping to stretch subsidy dollars, it can provide tenants with disposable income to achieve their personally important goals.

If for no other reason, employment assistance should be available early in the process of helping people leave homelessness because, contrary to stereotypes, homeless people do want to work and they often want to engage in work quickly. Research supports the claim that given the opportunity and support to do so, homeless people with multiple disabilities can work, including those who are chronically homeless (Marrone 2005; Rog and Holupka 1998; Theodore 2000; Trutko et al. 1998). Over time, earned income and duration of labor force attachment increases among people with disabilities who have been homeless (Cook et al. 2001; Long and Amendolia 2003); among individuals with substance use disorders (Zlotnik et al. 2002); and among veterans (Humphreys and Rosenheck 1998).

Our communities and economies rely on people working. It is what we do: a key to how we define our lives and how we meet our physical, emotional, and often our intellectual needs. Life has a two-fold foundation: the compulsion to work, which is created by external necessity, and the power of love (Freud 1930). Both are fundamental human characteristics that help integrate people into their families, communities, and societies. Yet, many professionals believe that work is too stressful for people with serious mental illness; they fear that people could relapse if they return to work. There is little research to support that claim. In fact, it is the other way around. Long-term unemployment has an unhealthy, negative health impact. Without work and without daily productive activity to cement relationships 
and support systems, people can become isolated, withdrawn, disengaged, and selfabsorbed in their illness and symptoms. For these reasons and others, it is a good time to explore the role employment plays in ending chronic homelessness and how it can best be offered to homeless job seekers.

\section{Homeless People and Tenants of Supportive Housing Work}

The largest demonstration project about homelessness and employment (the Job Training for the Homeless Demonstration Program [JTHDP]) was led by the U.S. Department of Labor over a seven-year period (Beck et al. 1997; Trutko et al. 1998). Even though some homeless individuals lacked the education and occupational training/experience to qualify for higher-paying jobs, their urgent need for income and housing often meant work had to come first and longer-term occupational training later. Job search assistance for these participants required programs structured so that homeless individuals could move from intake through assessment, a job search workshop, and job placement activities within a three-week period. Researchers found that with the appropriate blend of assessment, case management, employment, training, housing and support services, a substantial proportion of homeless individuals can secure and retain jobs and that this contributes to housing stability.

Other national employment initiatives demonstrated that employment services can be delivered on par with other social and supportive services linked to permanent housing. Findings from the Next Step: Jobs (NSJ) Initiative-a partnership among the Corporation for Supportive Housing (CSH), the Rockefeller Foundation, and nonprofit supportive housing providers in three cities-showed that providing both housing and employment can be successful, especially when lowimpact jobs are used as a starting point to build motivation to work (Long and Amendolia 2003; Rio et al. 1999; Rog and Holupka 1998). The Employment Intervention Demonstration Project (EIDP), which included some sites that serve people in transition from homelessness, found that providing rapid access to jobs was a more effective strategy to increase positive employment outcomes than requiring participation in extensive reemployment readiness services (Cook et al. 2001). Reporting on the SAMHSA-funded Access to Community Care and Effective Services and Support (ACCESS) program, which targeted mentally ill homeless individuals in a service collaboration model, Cook et al. (2001) and Min et al. (2004) concluded that these clients are best served by placing as great an emphasis on providing employment services as on providing housing and clinical treatment. Unfortunately, as is the case in many demonstration projects, when the funding for these demonstrations disappeared, the services they funded were either significantly reduced or discontinued.

Helping people get a job at a living wage is essential to end their homelessness. This means looking beneath whatever symptoms people have to uncover their core gifts, skills, and interests-in essence, "meeting them where they are at." Only by setting aside our preconceived notions of what constitutes "job-ready" can we hope to use employment as a tool to prevent or end chronic homelessness. 


\section{Confronting Personal, Program, and Systems Barriers to Making Work a Priority}

People who are chronically homeless have difficulties in securing employment because of the impacts of mental illnesses, substance abuse, or co-occurring disorders. A national study found that alcohol problems during the past month are reported by $38 \%$ of homeless clients, drug problems by $26 \%$, and mental health problems by $39 \%$. Sixty-six percent reported problems with one or more of these issues during the month before they were interviewed (Burt et al. 1999). In addition, these people commonly have other serious personal challenges. For example, to reenter the mainstream labor force, homeless people need interviewing skills and job credentials (Colorado Workforce Development Council \& Colorado Department of Labor and Employment 2004). Their mobile lifestyle and lack of a fixed address is a challenge when employment staff tries to connect them with jobs.

Although vocational rehabilitation and job training services exist to enable jobseekers, including those with disabilities, to obtain employment, people who are chronically homeless generally do not use them. They often do not experience state vocational rehabilitation (VR) services and One-Stop Career Centers as welcoming, and both Career Centers and VR agencies are usually unprepared to serve homeless job-seekers (Rivard and Akabas 1999). Employers view homeless individuals as less than desirable job candidates. These and a host of other significant challenges at the individual, program, and systems level impede the ability of homeless persons to get, keep, and advance in jobs at a living wage.

It is not uncommon for chronically homeless individuals to be unaware of mainstream employment resources or to resist formalized services. They may need help addressing a host of physical and emotional conditions before securing employment (Calloway and Morrissey 1998; Draine et al. 2002; Gonzalez and Rosenheck 2002; McGuire and Rosenheck 2004; Sullivan et al. 2000; Wright et al. 1998). Their distrust of traditional mental health or substance abuse treatment may keep them at arm's length from services and supports that could benefit them. Effective approaches for engaging people who are homeless and services-resistant begin by creating a welcoming environment in which individuals can explore or discuss employment services "with no strings attached." Strategies can include meeting with them on their turf - on park benches, under bridges, wherever they live- to have nonjudgmental conversations about a working life. Staff may offer to arrange a visit to an employment program in which the individual can talk with staff or peers about what the program does and how it helps people who are homeless. Outreach can include having job postings available at drop-in centers, regular coffee-time conversations with employment specialists, or opportunities to hear from peers who have found employment about how work has helped them lead more satisfying lives. These methods do not require prerequisites. Rather, they are slow entry-ramp methods that may help tip the scales from distrust, fear, and disinterest in work to motivation to consider and explore it.

We also know that many people who are homeless are already working at some type of job, even when they are on the street. Burt et al. (1999) concluded, "Almost half $(44 \%)$ of homeless clients did some paid work during the 30 days before being 
interviewed"' (p. 29). Of those who report working in the last 30 days, $20 \%$ did so in a job lasting or expected to last at least 3 months, $25 \%$ worked at a temporary or day labor job, and $2 \%$ earned money by peddling or selling personal belongings. Eight percent reported obtaining money through panhandling. The challenge is helping them move from the fringe economy to the mainstream labor force.

Integrating clinical treatment and employment services in the same program is confounded when staff hold conflicting expectations and priorities about client needs and goals, diverse perceptions of the role and importance of work, and different views about how needed services can be coordinated. Cross-training staff in mental health and employment issues, creating protocols for communication among team members, and providing opportunities for team planning can contribute to a more effective team approach (Quimby et al. 2001). Changing attitudes and practices requires effective staff training in employment-related skills and technologies, as well as attention to the organizational barriers that hinder the effective transferability of training to real-life settings (Corrigan et al. 2001). Failure to address either of these leaves significant impediments to achieving systems change (Waynor et al. 2005).

Fear of losing public entitlements can inhibit people with disabilities going to work, especially concerns about losing access to health care and cash benefits from the Social Security Administration (SSA). This is no less the case for people with disabilities who are homeless or tenants of supportive housing. Although revisions to the SSAs Ticket to Work program hold promise, they have yet to show significant increases in vocational outcomes. It is clear that a forced choice of either keeping health care and cash benefits or going to work is the wrong strategy. Rather, a flexible system of benefits that allows for the ebb and flow of employment among this population is needed. In a recent report, competitive employment was negatively associated with receipt of disability payments. Greater access to rehabilitation services was associated with greater participation in both competitive and noncompetitive employment. Although receipt of disability payments may have an adverse effect on competitive employment, providing rehabilitation services may ameliorate this tendency (Rosenheck et al. 2006).

Though we know that poverty is a key factor creating or exacerbating homelessness and that jobs at a living wage help people escape poverty, we are still a long way from integrating employment services as a key element in preventing and ending chronic homelessness. Federal homeless policy seems to be saying to states and communities that mainstream programs such as VR, Workforce Investment Act (WIA)-funded employment services, Community Services Block Grants, Medicaid, Mental Health and Substance Abuse Block Grants, and others should provide the services needed by homeless individuals and families. However, access to mainstream resources has not kept pace with the urgent need for services; when they are acquired, they are frequently insufficient. The inability to access funding for essential services such as employment is one of the most significant challenges for communities to end chronic homelessness.

When agencies think of job development and placement, they often think about referrals to VR services. Although national data specifically evaluating how well VR serves people who are homeless are not available, a number of studies show that 
nationwide, VR has been slow to address the needs of people with serious mental illnesses (Bevilaqua 1999; Noble et al. 1997), a disability that is prevalent among people who are homeless. Although the WIA that reorganized the mainstream employment and training system also mandates that its One-Stop Career Centers serve all job-seekers, job-seekers who are homeless may not be well served. Some advocates and service providers are concerned that WIAs performance accountability system may serve as a disincentive to states, local areas, or individual service providers to serve homeless people. The act requires states and local areas to set performance goals and track the performance of job training programs by measuring job placement rates, job retention rates, and the earnings of program participants, among other things. Although this performance-based approach is beneficial in many respects, it may inadvertently discourage programs and service providers from serving the most challenging populations, such as homeless people, whose outcomes are not likely to be as successful as those of other program participants (U.S. General Accounting Office 2000).

For most homeless assistance providers, priority one is getting people into housing with the treatment and supportive services that will reduce threats to health and safety and provide the foundation for community stabilization. However, not every moment is a job placement moment. People in Housing First programs may not be ready to get and hold a competitive job. They may fail employer drug testing, they still may be experiencing psychiatric symptoms, they may not show up on time, and they may still be having difficulties with personal hygiene. Job developers working with people transitioning from homelessness who appear to lack needed work behaviors risk their credibility and future job placements by referring someone not ready for work. Substance abuse counselors may resist their clients' involvement in employment because they have not demonstrated a certain number of months of sobriety and regular attendance at therapy sessions.

These are valid concerns. But the field has largely failed to recognize the role that the drive to achieve employment can play in the recovery process. When we talk about making work a priority, or a core service, we do not mean that people with serious mental illness and active substance use should be assisted to move from the streets and shelters directly into full-time, competitive jobs. Rather, we mean that the opportunity to perform some kind of work should be offered at the soonest possible moment rather than treated as an outcome of recovery. It must be integrated in the fabric of case management from the earliest efforts to engage people on the streets. The challenge we face is not only to shape the attitude that work is a core service activity, but to help programs build the capacity to offer employment services, whether directly or through an interagency integrated services team that includes an employment specialist, and to identify and use a variety of funding streams to support this effort.

\section{Why Implementing Work as a Priority Makes Good Sense}

'You haven't worked in a long time, perhaps a readiness training will help you...Come back when you're sober (or clean)... When you start coming to your 
appointments on time, then we can talk about working...You may not be ready for competitive employment-how about volunteering for awhile?", To a homeless job seeker, these statements are common and discouraging. They reinforce years of failure, hopelessness, and distrust and fail to present a promising pathway forward. In many instances, access to a job through an employment training program is not guaranteed, even if the homeless job seeker followed these suggested first steps. Perhaps because previous experiences were filled with promises broken by providers or because their best intentions to be good employees fell short at their last job, homeless job seekers tend to need work quickly and on their terms. It makes good sense to provide a credible, standing offer of work that engages people just as they are in the present moment.

Evidence gathered on the "Housing First" model demonstrates that people are more likely to keep housing (and develop motivation to address their treatment and rehabilitation needs) when housing is provided with no strings or prerequisites attached (Tsemberis et al. 2004). Similarly, experience in employment and training programs that target homeless job seekers is starting to show that offering work at the earliest opportunity when people ask for help motivates people who are chronically homeless to seek connections with service providers and address treatment issues.

There is also a "business case" for helping people who are chronically homeless to enter or reenter the labor force. Declining birthrates and an aging population will create serious challenges for employers seeking to hire and retain workers. The pool of available workers will shrink and employers must work harder to fill jobs. According to a recent study conducted by the National Association of Manufacturers, the workforce of the future is likely to come from three sectors: young people in transition from school to work, especially those enrolled in career development programs; low-skilled, low-wage, currently employed workers who are candidates for retraining; and "special populations", of unemployed or underemployed people who experience barriers to work. These include welfare recipients and people with disabilities. This implies that employers need to find ways to reach out and attract those who are chronically unemployed, such as people with mental illnesses and those who are homeless.

Downtown businesses realize the impact of street homelessness on their business community. In Dallas, for example, the effect on customers of panhandling or potentially odd or frightening behavior is a problem for merchants and customers alike. The city is investing in effective strategies that provide housing and services at the edge of the downtown district (Weinstein et al. 2004). The International Downtown Association, a trade association representing downtown business improvement districts (BIDs), seeks to give its members guidance on this issue. In addition to publishing a resource guide (Jackson et al. 2000), it has adopted a policy platform that includes addressing street homelessness and its impact upon downtown life by becoming more active participants in job creation efforts. 


\section{Implementing Work as a Priority}

Implementing employment services as a priority requires some changes in our service delivery system, funding schemes, our understanding of employment strategies and services, the clinical orientation in treatment services, and new partnerships, including One-Stop career centers. The following section provides some ideas and insights into how staff working in homeless assistance, housing, behavioral health, and workforce systems can adopt an integrated approach to addressing the vocational needs of homeless people.

\section{Shifting the Culture of Services}

We need to challenge the traditional assumptions about work. A homeless person's work skills are not only those that are indicated on their work history and resume but also those they use to survive on the streets. People who are homeless are resilient and creative in finding sources of income. They may not report to an office at 8 AM every day, but they do adhere to their own "work schedules." They know where to be and for how long if they are to make the maximum amount of money from panhandling. They have their own "business territories." Their ability to survive in their own "workplaces" should be acknowledged.

Applying standard work readiness criteria (recent work history, marketable skills, defined job goals, education, and a current resume) will lead to the conclusion that most homeless job seekers are not ready for work. It is true that behavior change will take time, motivation, and patience. If outreach workers start talking to individuals about employment as they hand out food, tokens, and blankets, the stage is set to help shape clients' self-perceptions about work and motivation to try a job (Lorello and Shaheen 2006). It may take months of speaking with a homeless person before he or she feels comfortable enough to come into the office to get assistance. If outreach workers and services staff are able to respond quickly and affirmatively to a person's expressed interest in work by not only helping the individual recognize inherent skills he or she possesses as part of daily survival, but also by offering a flexible, low-impact job, they will have laid the foundation for a new working life.

Making work a priority works best when homeless persons drive the process of their recovery and the design of the programs helping them (Shaheen et al. 2003). Programs need to institutionalize a culture of personal empowerment. Establishing an in-house peer advisory committee with real authority to make decisions about employment services is one effective method. It sends a message that the agency is serious about partnering with those it serves to help them attain their goals.

There are a number of documented practices that bring the mission of employment services "to market." The first is "vocationalizing" service and housing environments so that helping people access work opportunities becomes an expectation of all program staff (Parkhill 2000). On the street, outreach workers could provide information about employment services and no-obligation visits to employment programs. Drop-in centers could post job announcements and have regular speakers about employment services. Supportive housing staff could provide resources for job searching and access to work clothes and phones. 
Make a Credible, Standing Offer of Work

Jobs with a nonprofit agency, a social purpose business venture, or community employers that include flexible readiness criteria, schedules, and tasks can engage homeless job seekers who want to work quickly and may help them shun lengthy work preparation programs. Agencies can look inward and analyze what jobs they could offer that consumers could do on a flexible, part-time basis. Alternatively, they could address the day labor cycle that most people who are homeless find themselves in by starting their own supportive temporary/day labor enterprise. The objective is to help people realize how important a job is to them so that the desire to keep a job builds determination to address their issues of substance use or access to mental health treatment.

\section{Addressing Systems Fragmentation}

Community planning efforts to end chronic homelessness through employment and housing need to address the fragmentation and duplication across key systems. The various agencies that address housing assistance, mental health, substance abuse, and employment have their own planning processes and seldom reference each other. Continua of Care plans and Ten-Year Plans to End Homelessness must include strategies to help homeless people meet their financial needs through income support programs and through employment and training services. Workforce Investment plans can incorporate strategies to address the employment needs of homeless job seekers. Communities can also make a larger impact in reducing homelessness and increasing workforce participation if community mental health plans, public housing authority plans, and vocational rehabilitation plans are aligned to help end chronic homelessness.

Practitioners and their agencies can contribute to these community plans in a variety of ways, whether by conducting needs assessments, attending public hearings on plans, or by developing partnerships with mainstream workforce services to design local strategies for homeless job seekers. For the homeless person as well as for these disparate planning systems, fragmentation results in wasted opportunity, misdirected or duplicative resources, and communities unable to realize their full potential because there is no common vision or strategy for addressing homelessness through employment. Communities' strategies to end chronic homelessness should include ongoing resource mapping to determine how disparate systems can better align resources, meet the needs of employers, and provide seamless access to employment services for people who are chronically homeless. A recent study documented how collaboration between the homeless assistance and workforce system can result in effective employment services for people who are homeless (Henerson-Frakes 2004).

\section{Build Employment Capacity}

There may not be enough resources for homeless services agencies to provide the full range of required case management, housing supports, and treatment services in 
addition to developing a full-scale employment program. Case managers are required to do a great number of things all at once. They need to develop trust, provide access to housing, coordinate treatment and supportive services, provide disability benefits assistance, help people with their legal issues, and more. Case managers may not understand how to do job development and placement and their agencies may not have a trained employment specialist. However, this does not mean that agency staff cannot possess a general understanding of effective employment practices and integrate conversations about work into their day-to-day helping tasks. These conversations can also be used as opportunities for informal assessments of a consumer's strengths, needs, gifts, and skills and yield information that can be useful to the vocational team later on if the person enters formalized vocational services. Cross-training of staff develops practitioner alliances and increases the efficiency of programs in each system. When the supportive housing case manager has a working relationship with the vocational rehabilitation counselor or the Disability Program Navigator at the One-Stop career center, it is more likely the client will be well served.

The effective use of work incentives constitutes a technical challenge that can be met with training and developing expertise. From the Earned Income Disregard available in HUD housing programs to the work incentives associated with SSI and SSDI programs, employment and training programs need personnel who are knowledgeable and skilled in helping job seekers prepare to make use of these incentives. It is important that case managers who are skilled at helping homeless people with disabilities apply for and receive SSI also understand the impact of work on benefits so they can help their clients pursue employment goals without fears based on bad information.

Culturally competent practice is important when designing and implementing effective employment strategies. Staff should seek to increase their awareness of cultural differences so they can support homeless job seekers in building hope, selfesteem, and trust. Training can uncover culture-bound biases, teach staff to see the role of work through diverse cultural lenses, and enlarge staff members' base of knowledge and skills in helping people who may be different from themselves.

Programs should seek ways to leverage additional resources, both within and outside the agency, to ensure that their customers get employment assistance. For example, they should look at the part-time, temporary, and volunteer opportunities that may be available in their agency and make them available to consumers on a part-time, wage-paying basis to build motivation and skills in employment.

\section{Replicating What Works}

Lessons from the JTHDP program demonstrated that job training and employment programs work best for homeless people when they are combined with supportive services and housing (Trutko et al. 1998; Beck et al. 1997) and lessons learned from the EIDP demonstrate the importance of rapid access to jobs (Cook et al. 2001). These principles are core elements of the SAMHSA/Center for Mental Health Services (CMHS) Toolkit on Supported Employment (SE). The SE Toolkit is currently being enhanced with a supplement for people who are homeless that uses a 
"menu" approach grounded in the principle that there is no wrong door to employment. Meeting people "where they are at" means that people should have options to engage in work even in the earlier stages of recovery. The primary modification to SE practice is recognizing that people recovering from homelessness often need a slower entry ramp to jobs and can benefit from the ability to choose from an array of individualized options in addition to a 'fast track' into the competitive labor market. As Fig. 1 shows, recognizing work as a priority begins during outreach. For those who want to enter into employment, a brief assessment explores the individual's gifts, skills, and interests. Getting people into jobs quickly is preferred, but the individual chooses whether to proceed directly to full or parttime jobs or take a slower path ("discovery" options) to further solidify preferences and build self-confidence. Whatever path the individual chooses, he or she is guided by employment specialists who help negotiate the employment process or assist in making course corrections if needed. This approach is consistent with the key evidence-based Supported Employment principles that lead to better employment outcomes such as "zero exclusion" (people are not precluded from participation based upon severity of disability) "rapid access to competitive jobs" (getting people into real work for real pay quickly) and "time-unlimited services for job

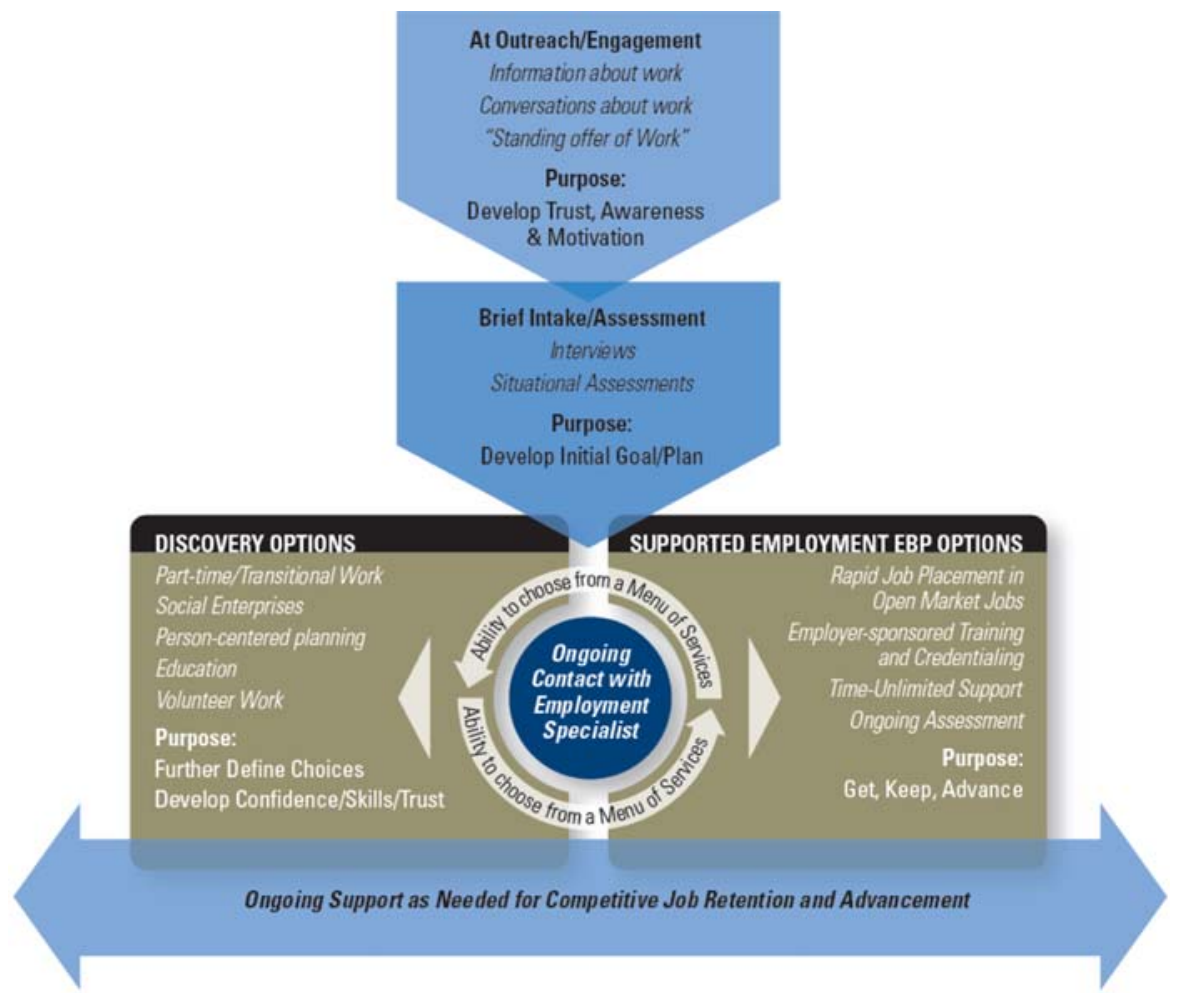

Fig. 1 The menu of employment services that should be available to people who are homeless to prioritize rapid access to competitive jobs while offering supportive services 
retention, continuous assessment and advancement" (ongoing support to maintain and advance in the job for as long as needed) (Center for Mental Health Services 2003).

Despite significant challenges, the use of employment as a tool for ending homelessness, particularly by offering opportunities for work at the earliest opportunity, is gaining ascendancy. Across the country, a number of homelessness services agencies are making significant strides in using work as a means of preventing and addressing chronic homelessness. For example:

- They are breaking the link between chronic homelessness and chronic poverty by building partnerships for job development and income supports;

- instead of parallel and often clashing systems, they are establishing a larger community vision to make work as a priority in addressing homelessness;

- they are helping staff build the attitudes and skills they need to address employment in ways appropriate to the consumer's stage of recovery and readiness for change;

- they are partnering with the mainstream workforce system (and its traditional partners from the employer and economic development sectors) to help these agencies realize that homelessness is also their problem and that they can help address it through employment; and

- they are seeking new resources to support employment for this population and blending and braiding funding streams more effectively to build employment capacity.

\section{Seek New Partners}

Preventing and ending homelessness is not only the job of service providers, but should be high on the agenda of the whole community as well. In discussing the responsibilities of a civil society, Streeter (2002) states that communities need to move beyond charitable approaches to develop a multi-sector approach that addresses poverty, social inclusion, and community health. He posits that a multisector approach involving stakeholders from the business and faith communities, community-based organizations, and public services agencies would result in a higher tide capable of lifting all boats. A solid partnership ensures that everyone in the community ultimately has a stake and a role in addressing poverty. Collaborations among diverse partners with diverse interests can leverage more in the way of resources, knowledge, and expertise than any one sector working alone.

Provider staff can actively promote the possibility of work with the people they serve by building partnerships with community organizations. For example, if they have a relationship with a faith-based organization food pantry, they could talk to the congregation leaders about providing volunteer jobs, cosponsoring a grant application to a foundation that would bring in new resources to support employment services, or using their influence to help obtain funding for this purpose from resources targeted for community economic development. Working with BIDs to obtain contracts for jobs such as cleaning or renovation may provide chances for people to reenter employment at their own pace and build job skills and 
credentials (Shaheen et al. 2003). Case managers and other staff that "own'" the employment function can use their inherent creativity, familiarity with the community, and knowledge of the homeless population to leverage new resources to help people get jobs.

\section{A Tale of Two Projects}

The following projects in Los Angeles and Indianapolis illustrate strategies in which employment services are not only an integral component to ending homelessness, but are offered early on to people who are homeless or moving into permanent housing. Employment programs serving people who are homeless are often provided in diverse settings, by diverse partners and with diverse methods, funding and outcomes tracking. The examples cited represent two programs with contrasting elements but with compatible goals - that of engaging and supporting people who are homeless in employment. These projects differ in a number of respects. Most notably, the Indianapolis project serves a substantially smaller number of participants, over an extended period of time, in a single site permanent housing environment. This contrasts with the Los Angeles project, which serves a large number of guests in a temporary shelter environment. Combined, these projects demonstrate the range of services that can be delivered in innovative ways to increase access and participation in the workforce for people with disabilities who are homeless.

\section{Los Angeles: A Portal to Employment}

The City of Los Angeles Homeless Services Agency and the Workforce Development Division of the Community Development Department (CDD) partnered to link a large homeless shelter and a WorkSource Center (a WIAfunded One-Stop career center) to serve homeless job seekers downtown. The support for this effort was made possible by a federal grant from the Office on Disability Employment Policy (ODEP) to CDD to end chronic homelessness through employment and housing.

This emergency shelter houses 300 men and 150 women nightly and is the largest shelter of its kind in Los Angeles County. The partnership was the result of observations made by a focus group comprised of shelter residents. The general consensus was that the "self-directed" services routinely provided at the WorkSource Center were intimidating and uninviting to individuals who were homeless and that lack of computer skills limited their successful utilization of available core services.

Shelter guests in the focus group recommended establishing a "portal" at the shelter that would replicate a resource room of a One-Stop with "self-directed employment search", services readily available. Their vision was honored when the shelter established such a portal, with operating hours between 4:30 pm and 9:30 pm. Two WorkSource Center resource specialists now provide orientation to the One-Stop system, teach classes on basic computer skills, and assist customers in 
navigating employment-related websites, including online job postings. Like all Worksource Center customers, shelter guests are registered in the mainstream workforce system and issued swipe cards that enable them to access services in the One Stop system during the daytime hours. Personal e-mail accounts are available, and shelter participants register in the State of California Employment Development Department (EDD) Cal Jobs referral system as well as the City of Los Angeles Skills Match system. Additional services include classes (available in Spanish or English), legal assistance workshops, and referral to General Equivalency Diploma (GED) courses available through the WorkSource system.

The New Image/New Hope EmployABILITY Resource center is open five nights weekly. It includes seven computer stations, a copier, fax machine, Closed-Circuit $\mathrm{TV}$, a height-adjustable workstation with a large screen monitor, and DSL connectivity. Interested clients may attend orientation and beginning computer classes, which are provided in both English and Spanish. The resource center staff conducts initial "discovery" interviews, assists clients in preparing resumes and master applications, and facilitates shelter guests' use of online vocational assessment programs to help them identify their employment interests. During the six quarters from April 2005, when the service opened, to September 2006, the portal served 767 individuals (unduplicated) and placed people in 175 jobs for an entered employment rate of $22.8 \%$. On average, a shelter guest who registers for employment assistance in the shelter makes 12.4 visits to the resource room for assistance (S. Quigley, Personal communication 2006).

\section{Indianapolis: A Journey Home}

Indianapolis Private Industry Council, the administrative agent for the Local Workforce Investment Board, established the Threshold Project using funding from a joint initiative sponsored by the U.S. Departments of Labor and Housing and Urban Development that was intended to end chronic homelessness through employment and housing. The collaborative project includes the City of Indianapolis; HealthNet's Homeless Initiative Program; Goodwill Industries of Central Indiana, Inc.; Easter Seals Crossroads; and Luther Consulting, LLC. Serving people with mental illness, substance abuse, or co-occurring disorders who have been homeless for a year or longer or who have had at least four episodes of homelessness over a three-year period, the Threshold Project reaches out to people who are living on the streets or in shelters and simultaneously offers them a permanent housing unit and help finding a job.

The housing includes 42 units of one-bedroom apartments located within a garden style apartment complex in the City. The units are subsidized by HUDs Shelter Plus Care voucher program under the McKinney-Vento appropriation. Customized employment services identify an individual's strengths, goals, and vocational desires and interests and help find a job that uses them. The project teaches employers how to work with at-risk populations and guides them in making reasonable accommodations to allow an individual to succeed on the job.

In mid-2004, after spending the past 18 months on the streets and in shelters, Robert talked with the Resource Coordinator with the Homeless Initiative Program 
and the Employment Counselor with Crossroads, two staff dedicated to the HUD/ DOL Collaborative. "I definitely wanted to be a part of it," he says. "I started crying when I got accepted.' When he moved into his new apartment a month later, he said "I was blown away. I thought, 'This is mine... my apartment.", At the time, he was enrolled in a culinary training program offered by Second Helpings in Indianapolis and graduated shortly after moving into his apartment. "Cooking is my thing," he says. "It was a joy to finally accomplish something." Certified as a chef, he is now employed at a local major health care facility. His job pays him $\$ 11.50$ per hour with comprehensive benefits. Robert states that this is the first time he has made this much money in his life. "I love my job... great benefits."

Over 30 months, since it opened its doors, $66 \%$ of the tenants entering the project from the streets and shelters have maintained their housing and $68 \%$ entered full or part-time competitive employment (R. Richardson, Personal communication 2006).

\section{Conclusion}

We have learned that people who are homeless, including those who are chronically homeless, can, with the right opportunities and support, achieve employment success. We know that when people are offered what they say they want, they can rise to the occasion and make great progress in escaping homelessness. We know that in addition to a safe and affordable home, they want to work, but jobs at a living wage have eluded them for a host of personal, program, and systemic reasons. As employers look to nontraditional populations to address a thinning workforce, people who are presently homeless, given the right opportunities and supports, may be able to compete effectively for those jobs.

The challenge we face today is to look beyond the current face of disability and homelessness and beyond the walls of the disability services systems that often result in parallel, not mainstream, services. We must widen our vision to include new partnerships and collaborations that can provide people who are homeless a chance to do better. Work can become a strong bridge to recovery. By making work a priority, programs can help consumers advance from hopelessness and joblessness to a life as a valued member of a community, an employee with a future.

\section{References}

Beck, S. K., Trutko, J., Isbell, K., Rothstein, F., \& Barnow, B. (1997). Employment and training for America's homeless: Best practices guide. Washington, DC: U.S. Department of Labor.

Bevilaqua, J. J. (1999). The state vocational rehabilitation agency: A case for closure. Journal of Disability Policy Studies, 10(1), 90-98.

Burt, M., Hedderson, J., Zweig, J., Ortiz, M., Aron-Turnham, L., \& Johnson, S. M. (2004). Strategies for reducing chronic street homelessness. Washington, DC: U.S. Department of Housing and Urban Development, Office of Policy Development and Research.

Burt, M., Aron, L. Y., Douglas, T., Valente, J., Lee, E., \& Iwen, B. (1999). Homelessness: Programs and the people they serve. Findings of the national survey of homeless assistance providers and clients. Washington, DC: U.S. Department of Housing and Urban Development (ERIC Document Reproduction Service No. ED438347). 
Calloway, M. O., \& Morrissey, J. P. (1998). Overcoming service barriers for homeless persons with serious psychiatric disorders. Psychiatric Services, 49, 1568-1572.

Center for Mental Health Services (2003). Evidence-based practices: Shaping mental health services toward recovery. Supported employment toolkit. Retrieved February 21, 2007, from http:// mentalhealth.samhsa.gov/cmhs/communitysupport/toolkits/employment.

Colorado Workforce Development Council \& the Colorado Department of Labor and Employment (2004). Colorado: Formula for success. WIA Program Year 2004 Annual Report. Denver: Colorado Workforce Development Council \& the Colorado Department of Labor and Employment.

Cook, J. A., Pickett-Schenk, S. A., Grey, D., Banghart, M., Rosenheck, R. A., \& Randolph, F. (2001). Vocational outcomes among formerly homeless persons with severe mental illness in the ACCESS program. American Psychiatric Association, 52(8), 1075-1080.

Corrigan, P. W., Steiner, L., McCracken, S. G., Blaser, B., \& Barr, M. (2001). Strategies for disseminating evidence-based practices to staff who treat people with serious mental illness. Psychiatric Services, 52(12), 1598-1606.

Culhane, D. P., Metraux, S., \& Hadley, T. (2001). The impact of supportive housing for homeless persons with severe mental illness on the utilization of the public health, corrections and emergency shelter systems: the New York-New York initiative. Housing Policy Debate, 13(1), 107-163.

Dixon, L. B., Krauss, N., Kernan, E., Lehaman, A. F., \& DeForge, B. R. (1995). Modifying the PACT model to serve homeless persons with severe mental illness. Psychiatric Services, 46(7), 684-688.

Draine, J., Salzer, M. S., Culhane, D. P., \& Hadley, T. R. (2002). Role of social disadvantage in crime, joblessness, and homelessness among persons with serious mental illness. Psychiatric Services, 53, $565-573$.

Freud, S. (1930). Civilization and its discontents. New York: W.W. Norton \& Company.

Gonzalez, G., \& Rosenheck, R. A. (2002). Outcomes and service use among homeless persons with serious mental illness and substance abuse. Psychiatric Services, 53, 437-446.

Henerson-Frakes, J. (2004). Serving the homeless through the One-Stop system: a case study. A briefing paper prepared as part of the national evaluation of the implementation of WIA final report. Berkeley, CA: Social Policy Research Associates.

Hopper, K. (2003). Reckoning with homelessness. Ithaca, New York: Sage House.

Humphreys, H., \& Rosenheck, R. (1998). Treatment involvement and outcomes for four subtypes of homeless veterans. American Journal of Orthopsychiatry, 68(2), 285-294.

Jackson, E., Kligerman, D., Barget, J., \& Cecil, G. (2000). Addressing homelessness: Successful downtown partnerships-A report of strategies to assist homeless persons with mental illness. Washington, DC: International Downtown Association.

Long, D., \& Amendolia, J. (2003). Promoting employment for homeless people: Final cost-effectiveness study. Bethesda, MD: Abt Associates.

Lorello, T., \& Shaheen, G. (2006). From outreach to employment: Enhancing motivation to change. Issues Brief No. 4 in "Work as a Priority"' Series. Manuscript submitted for publication.

Marrone, J. (2005). Creating hope through employment for people who are homeless or in transitional housing. American Journal of Psychiatric Rehabilitation, 8, 13-35.

McGuire, J. F., \& Rosenheck, R. A. (2004). Criminal history as a prognostic indicator in the treatment of homeless people with severe mental illness. Psychiatric Services, 55, 42-48.

Min, S., Wong, Y. I., \& Rothbard, A. B. (2004). Outcomes of shelter use among homeless persons with serious mental illness. Psychiatric Services, 55(3), 284-289.

Noble, J. J., Honberg, R. S., Hall, L. L., \& Flynn, L. M. (1997). A legacy of failure: The inability of the federal state vocational rehabilitation system to serve people with severe mental illnesses. Washington, DC: National Alliance for the Mentally Ill.

Quimby, E., Drake, R. E., \& Becker, D. R. (2001). Ethnographic findings from the Washington, D.C. vocational services study. Psychiatric Rehabilitation Journal, 24(4), 368-374.

Parkhill, P. (2000). Vocationalizing the homefront: Promising practices in place-based employment. New York: Corporation for Supportive Housing.

Rio, J., Russell, D., Dudasik, S., \& Gravino, L. (1999). Supportive housing-based employment services. American Rehabilitation, 25(1), 26-31.

Rivard, J. C., \& Akabas, S. H. (1999). Evaluation of the "linking supportive housing and vocational rehabilitation systems" project. New York: Center for Social Policy and Practice in the Workplace, Columbia University School of Social Work. 
Rog, D. J., \& Holupka, C. S. (1998). Reconnecting homeless individuals and families to the community. In L. B. Fosburg, \& D. L. Dennis (Eds.), The 1998 Symposium on Homelessness Research. Retrieved March 21, 2007, from http://aspe.hhs.gov/homeless/symposium/11-Reconn.htm.

Rosenheck, R., Leslie, D., Keefe, R., McEnvoy, J., Swartz, M., Perkins, D., et al. (2006). Barriers to employment for people with schizophrenia. American Journal of Psychiatry, 163, 411-417.

Shaheen, G., Williams, F., \& Dennis D. (Eds.) (2003). Work as a priority: A resource for employing people who have a serious mental illness and who are homeless [DHHS Pub. No. SMA 03-3834]. Rockville, MD: Center for Mental Health Services, Substance Abuse and Mental Health Services Administration.

Stein, L. I., \& Santos, A. B. (1998). Assertive community treatment of persons with severe mental illness. New York: WW Norton.

Streeter, R. (2002). Transforming charity: Toward a results-oriented social sector. New York: The Hudson Institute.

Sullivan, G., Burnam, A., Koegel, P., \& Hollenberg, J. (2000). Quality of life of homeless persons with mental illness: Results from the course-of-homelessness study. Psychiatric Services, 51, 1135-1141.

Theodore, N. (2000). Homeless who can't make enough to get ahead. Chicago: Day Labor Project, Chicago Coalition for the Homeless.

Trutko, J. W., Barnow, B. S., Beck, S. K., Min, S., \& Isbell, K. (1998). Employment and training for America's homeless: Final report of the job training for the Homeless Demonstration Program. Washington, DC: U.S. Department of Labor.

Tsemberis, S., Gulcur, L., \& Nakae, M. (2004). Housing first, consumer choice, and harm reduction for homeless individuals with a dual diagnosis. American Journal of Public Health, 94(4), 651-656.

Tsemberis, S., \& Eisenberg, R. F. (2000). Pathways to housing: Supported housing for street-dwelling homeless individuals with psychiatric disabilities. Psychiatric Services, 51(4), 487-493.

U.S. General Accounting Office (2000). Homelessness-barriers to using mainstream programs [GAO/ RCED-00-184]. Washington, DC: U.S. General Accounting Office.

Waynor, W. R., Pratt, C. W., Dolce, J., Bates, F. M., \& Roberts, M. M. (2005). Making employment a priority in community mental health: Benefits of demonstrating direct employment practice. American Journal of Psychiatric Rehabilitation, 8, 103-112.

Weinstein, B. L., Clower, T. L., Graves, J., \& Barnes, S. (2004). Improving services to Dallas' homeless: A key to downtown revitalization. Dallas, Texas: Central Citizens Association.

Wright, J. R., Beth, A. B., \& Devine, J. A. (1998). Beside the golden door: Policy, politics and the homeless. New York: Aldine De Gruyter.

Zlotnick, C., Robertson, M. J., \& Tam, T. (2002). Substance use and labor force participation among homeless adults. American Journal of Drug and Alcohol Abuse, 28(1), 37-53. 